\title{
Representation of Social Actors in Sexual Violence Issue in The New York Times and The Jakarta Post Newspapers: A Critical Discourse Analysis
}

\author{
Widya Evayani ${ }^{1}$, Akhyar Rido ${ }^{2}$ \\ widyaevayani@gmail.com ${ }^{1}$, akhyar_rido@teknokrat.ac.id ${ }^{2}$ \\ Universitas Teknokrat Indonesia ${ }^{1,2}$
}

\begin{abstract}
Sexual violence was a social issue that arises comprehensive responses and can happen to all layers of society regardless of position, age, or other social factors. The objective of this study is to reveal how social actors are represented in news reporting of sexual violence. The data were collected from the official website of The Jakarta Post and The New York Times. The findings show that to detach the actor (exclusion), both of newspaper mostly presented the actor especially the victim as a passive agent and the perpetrator as an active agent. The salient differences were found in the use of inclusion strategy. This confirms that The Jakarta Post presented the actor as specific individual such as by their gender, age, and occupation while The New York Times presented them by their surname and title such as "Professor".
\end{abstract}

Keywords: exclusion, inclusion, sexual violence, social actor

\section{Introduction}

As discourse has functioned both as media to transfer the knowledge and shape certain mental image, critical discourse analysis becomes one of the approaches in discourse that contributes to uncovering power and ideology behind issues (Fairclough,1995; Amalia, 2019). In social issues such as sexual violence, linguists also acquainted with the term Social Actor Representation which refers to how the actor(s) of social practice are depicted through a text. Furthermore, Fairclough (2004) stated that social actors refer to participants in clauses or they might not be. The actors also can be presented either intentionally or circumstantially using two strategies named exclusion and inclusion (Van Leeuwen, 2008) or personal and impersonal (Fairclough, 2004).

Accordingly, it is considered imperative to reveal how social actors in news reporting of sexual violence are represented in the newspaper as Pekkarinen (2016) stated that sexual violence is an issue that affects all parts of society and arises comprehensive responses since it brings massive impact for those who experience it. In the same vein, World Health Organization (2012) explained sexual violence encompasses acts that arrange from verbal harassment to forced penetration. Moreover, as nowadays, power and ideology have been closely related to mass media, a newspaper is considered as one of the strongest media to spread out the news which also influences public perception (Pekkarinen, 2016). Besides, the language used by journalists is possibly purposively taken with respect to achieving certain purpose, which is either to support or marginalize certain people, groups, or ideology. Hence, throughout the news that constantly being exposed, newspaper indirectly formed public perception. In addition, many parties speculate that there is injustice in presenting the news reporting on sexual violence since victims who are mostly women are portrayed poorly compare to perpetrators, so that perpetrators gain more sympathy from public, furthermore, as the basis of supposition, The Jakarta Post and The New York Times are choose as there 
might be some disparities in the way these two newspapers portray the news actor owing to distinction in perspective and background.

Moreover, many studies have discussed a critical analysis of social actors such as Risdaneva (2018) who investigated the portrayal of women in the news reporting of sexual violence. The findings indicate that the choices of the naming categories used by both newspapers to portray the perpetrator and victim are different. Pekkarinen (2018) conducted an investigation towards the actor of sexual violence in select US news articles. The result confirms that the victims were generally portrayed in terms that did not make them appear as active agents in control of their own and the alleged perpetrators were mainly either framed through their accomplishment in a field such as military or as monsters preying on their victims or even both. Qanitat (2015) examined the social actor representation on Islamic issues in two online newspapers. The findings show both of the newspaper adopts exclusion strategy, the inclusion strategy consisted of activation, genericization, assimilation, differentiation, categorization, as well as overdetermination.

To this end, this study is aimed at analyzing how social actors are represented in news reporting sexual violence in The New York Times and The Jakarta Post newspapers. This research is expected to give the reader an overview of the types of the strategy adopted by journalists in representing certain people, group of people, or an ideology through the diction and phrases they used in texts.

\section{Theory and Method}

The researchers employed Van Leeuwen's (2008) theory about social actor representation particularly about exclusion that consists of suppression and backgrounding and inclusion which focus on activation, passivation, specification, categorization, and nomination. Van Leeuwen (2008) states that representations include or exclude social actors to suit their interests and purposes in regards to whom they are intended (readers). This model focused on how one is positioned in an inappropriate position and the others in a higher position. The following figure is the complete divisions of the Social Actor Network (SAR) network proposed by Van Leeuwen (2008: 52).

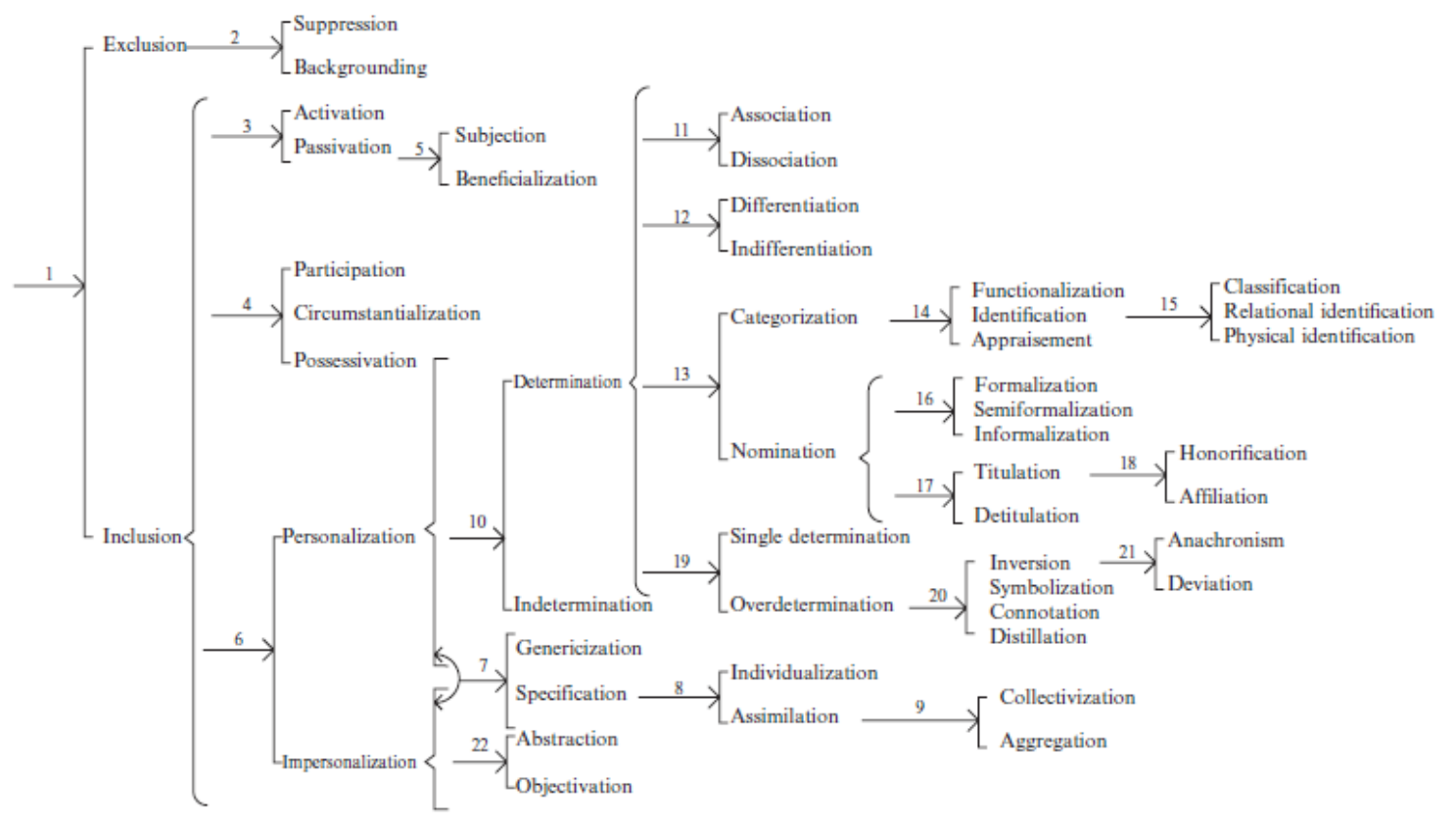

Figure 1. Social Actor Network (Van Leeuwen, 2008: 52) 


\section{Exclusion}

Exclusion is the process of omitting actors by some linguistic mechanisms. It has two main subdivisions: suppression and backgrounding. The main difference between suppression and backgrounding is the point that they leave a trace or not within representation (van Leeuwen, 2008). The description of both subdivisions will be explained below.

\section{a. Suppression}

Suppression is the exclusion that leaves no traces in the representation, excluding both the social actors and their activities. Van Leeuwen (2008) calls this kind of exclusion as radical exclusion. The linguistic realization of suppression can be realized in some ways; (1) Passive agent deletion. The function of this realization is to omit or delete the real actor (s). For example: "A church service was held at Cambustar church in Saint-Andre on Saturday in memory of the 239 people on board of the flight. (Qanitat, 2015). (2) Non-finite clauses (e. g., infinitival clauses). For example. "To maintain this policy is hard" (van Leeuwen, 2008:29). (3) Nominalizations and process nouns. For example "The level of support for stopping immigration altogether was at a postwar high" (van Leeuwen, 2008:30).

\section{b. Backgrounding}

Backgrounding is the exclusion that leaves traces in the representation. Here, the excluded social actors in a specific activity appear later in another part of the clause, sentence or text. According to van Leeuwen (2008: 30-31) the linguistic realization of backgrounding can be existed from simple ellipses in nonfinite clauses with -ing and -ed participles, in infinitival clauses with to, and in paratactic clauses. The example is "Speaking in the Commons earlier on Monday, the Prime Minister said he would use the telephone call to put pressure on the newly re-elected Netenyahu to commit to talks on two-state solution.' (Qanitat, 2015)

\section{Inclusion}

Inclusion strategy is the process of showing or presenting the actor of a particular action within the discourse. Inclusion is divided into many subcategories based on van Leeuwen's (2008) framework (refer to Figure 1). Yet, in this strategy, this study will concern on five sub categories, they are; (1) activation, (2) passivation, (3) specification, (4) categorization, (5) nomination.

\section{a. Activation}

Activation occurs when social actors are represented as the active, dynamic forces in an activity e.g Obama avoids calling the attack an example of Islamic extremism (Qanitat, 2015).

\section{b. Passivation}

Passivation is used when the social actors are represented as 'undergoing' the activity, or as being 'at the receiving end of it' (Qanitat, 2015:19). Passivated social actor can be subjected or beneficialised. Subjected social actors are treated as objects in the representation, for instance as objects of exchange, this process called Subjection. While Beneficialized social actors form a third party which, positively or negatively, benefits from the action, this also called Beneficialization, for example, "Australia was bringing in about 70,000 migrants a year". Here the "about 70,000 migrants" are subjected to the activity of "bringing in" 


\section{c. Categorization}

Categorization occurs when social actors are represented both in terms of their unique identity, by being nominated, or in terms of the identity and function they share with others. It has three subdivisions; Functionalization, Identification, and Appraisement. Functionalization occurs when social actors are referred to in terms of an activity, in terms of something they do. Identification occurs when social actors are defined, not in terms of what they do, but in terms of what they are. Van Leeuwen (1996) distinguishes three types: classification, relational identification and physical identification. Classification refers to conditions when the social actors are represented in terms of the major categories by means of which different classes of people are differentiated. The categories include: age, gender, provenance, class, ethnicity, etc. Relational identification represents social actors in terms of their personal, kinship or work relation to each other, and is realized by a closed set of nouns denoting such relations as "friend", "aunt", "colleague". Physical identification refers to terms representing social actors in terms of physical characteristics which uniquely identify them in a given context as in: "A little girl with a long, fair pigtail came". Besides, social actor can be presented interpersonal, rather than experiential terms, or it called Appraisement. Social actors are appraised when they are referred to in terms which evaluate them as good or bad, loved or hated, admired or pitied. This is realized by the set of nouns and idioms that denote such appraisement, for instance "the darling", "the bastard", "the wretch" or "thugs" (Van Leeuwen, 2008).

\section{d. Nominations}

Nomination means social actors are presented in terms of their unique identity and are usually manifested with proper nouns and divided into formalization (only definite names, with or without honorifics), semi formalization (given a name and a sure name), and informalization (given only names), for example "Sultan Turki, return my diamond button" (van Leeuwen,2008: 41). Nominations may be titulated (Titulation), either in the form of honorification, the addition of standard titles, ranks, etc., as with "Dr."

\section{e. Specification}

Specification may be realized by the singular, and can result by several ways. First, Individualization; Social actors can be referred to as individuals: "The ministry for sport and Recreation; Mr. Brown, said ....", Second, Assimilation; Social actors can be referred to as groups which are realized by plurality, by a mass noun or a noun denoting a group of people, as "this nation" and "the community".

This study used a qualitative method. The articles from The Jakarta Post and The New York Times were chosen under several considerations; (1) the actor who is involved, both the victim and the perpetrator is either respected person or prominent figure who has authority or fame, (2) the level of violence, the issue that attract the attention or response from local or international. The data were collected through several steps; (1) collecting eight articles on sexual issues in each online versions of the newspapers published from July to November 2018. (2) Narrowing the data to small numbers by choosing specific topics and based on characterization. (3) Organizing news based on the time of publication. After collecting the data, they were analyzed through several steps; (1) Reading the whole data three times to get an overview of the discussion of the article. (2) Breaking down the collected data in the form of articles into sentences. Data were encoded based on the participants involved and actions attached to them. (3) Categorizing the data based on the theory proposed by Van Leeuwen (2008). (4) Presenting the data based on its categories of strategies used. (5) Identifying any differences in strategies between the two newspapers. (6) Presenting the findings based on the themes. (7) Concluding the findings. 


\section{Findings and Discussion}

This study analyzed the representation of social actors in sexual violence issues publish in The Jakarta Post and The New York Times online newspapers using the social actor-network theory by Van Leeuwen (2008). He mentioned that the actors can be presented by two strategies called inclusion; when actors attach in the news and exclusion; when actors detach from the news.

After analyzing the data, the findings revealed some salient distinctions and even similarities in the way each of the newspapers attaches or detaches the social actors. In the exclusion strategy, The Jakarta Post and The New York Times detach one of the actors and direct the readers' views into others, so that other actors become unnoticed. Specifically, in the backgrounding, the main distinction lies in the purpose of each newspaper in using exclusion strategy; in The Jakarta Post, this strategy is used to emphasize the severity of problems that occur in victims, while The New York Times uses this strategy to suppress the condition of the victim. Thus, the perpetrators are free from their responsibilities.

In an inclusion strategy, the researchers find similarities in the application of strategy that relates to the newspapers' preferences in each to activate actor(s) in the news or make them as a passive party. Both of newspapers activate the social actors, specifically, suspects in explaining the sequence of problems or chronology of the problem. A perpetrator is represented as a party who actively controls the victim and uses his position and power to control the victim, while the victim is more represented as a passive party and must accept an action.

Moreover, The Jakarta Post presents more social actors using assimilation strategies. In this case, social actors are not clearly stated and detailed in their identities but are represented as a group of people characterized by the use of plurality such as "minors". Meanwhile, The New York Times presents more actors individually. The journalist provides information to the reader about the name of actors accompanied by the occupation or achievements of the actors to give more detail and specific information. On the other hand, The New York Times mostly classifies social actors; both perpetrators and victims according to their age and gender, while The Jakarta Post tends to function them in terms of their occupation. These different choices imply that The New York Times tends to be considerably personalized the actor rather than functional them as The Jakarta Post does.

Another distinctive feature is related to the using of nomination strategy. The salient distinction is that The Jakarta Post only uses formalization and informalization strategy, while The New York Times use semiformalization, formalization, and honorification. This difference indicates that in the American context, it is very unusual to call someone by their first name because this happens if the person has a close relationship and knows each other well, while in the context of The Jakarta Post, as a representative of the Indonesian people, it is very rare to refer to someone with an academic degree such as "doctor" or "professor", this presumably happened because naming system in the Indonesian context is rather different from the English. Indonesia does not have fixed rules for it. This is also caused by the fact that many Indonesian people only have one name without a family or surname.

\section{Exclusion}

In this type, actors of certain social practice possible to be excluded from the text. It can be realized by two strategies according to the theory, they are suppression and backgrounding.

\section{Suppression}

In the suppression strategy, the actors are excluded, thus, there is no reference to the social actor (s) in question anywhere in the text (Van Leeuwen, 2008).

4.1 The letter alleges several acts of humiliation and sexual intimidation, including "semisecret" photographic sessions in which dancers were singled out with offers of money and urged to take drugs to "feel more free". (The Jakarta Post, September 13, 2018 edition, world column) 
4.2 These kids are terrorized, they are being shamed and blamed (The New York Times, November 23, 2018, Canada Column, Catherine Porter)

Datum 4.1 taken from the article entitled "Belgian art star Jan Fabre accused of sexual harassment". The use of the suppression strategy is to direct the reader's attention into one party, therefore, the involvement of another party in the action became less valued. Meanwhile, datum 4.2 obtained from an article entitled "St. Michael's, a Toronto All-Boys School, Is Rocked by Accusations of Sexual Assaults". In this case, the victims "these kids" which refer to students in the school is marginalized or presented as the party who received the impact of the action of the sexual assault. Despite the actions taken, the victims who were subjected to, and the impact they caused were explained in the clause, but it was not clearly explained who was terrorizing and who embarrassed "these kids".

\section{Backgrounding}

In backgrounding, the excluded social actors may not be mentioned about a given action, but they are mentioned elsewhere in the text, and we can infer with reasonable (though never total) certainty who they are (Van Leeuwen, 2008). Both newspapers use this strategy to delay the presence of social actors so that the position of the actor becomes retarded.

4.3 Wearing a black headscarf, Nuril sat and sobbed in front of her rented home in Mataram on Monday afternoon while a camera recorded her message to the President. (The Jakarta Post, November 14, 2018, National column, Gemma Holliani Cahya)

4.4 Casting himself as a "well-respected retail executive," he claimed that the bookseller had enabled rumors that he was let go because of "serious sexual misconduct." (The New York Times, August 29,2018, Business Column, Tiffany Hsu and Alexandra Alter)

Data 4.3 and 4.4 confirm that the actors of the news or specifically the victim are mentioned after the infinite clause-ing, in which it inherently explains that backgrounding strategy is used. Datum 4.3 taken from the article entitled "Jailed for reporting her alleged sexual offender, Mataram woman cries for help", and $\mathbf{4 . 4}$ taken from the article entitled "Barnes \& Noble Says Former C.E.O. Demos Parneros Was Fired for Sexual Harassment". In 4.3, backgrounding strategy is used to emphasize the situation experienced by the actor while in $\mathbf{4 . 4}$, it aims to reduce the number of social actors in a given time.

\section{Inclusion}

Inclusion strategy is the process of showing or presenting the actor of a particular action within the discourse. Inclusion is divided into many subcategories based on Van Leeuwen's (2008) framework, moreover, this study will only focus on five sub-strategies; (1) activation, (2) passivation, (3) specification, (4) categorization, and (5) nomination.

\section{Activation}

Activation strategy occurs when social actors are represented as the active, dynamic forces in an activity. The use of an activation strategy in the sentence aimed to clearly show the social actor and emphasize it to the readers. The data are as follows:

4.5 He seduced his targets just like the way people seduce their romantic partner (The Jakarta Post, June 6, 2018, National Column, Fadli)

4.6 Professor Kelley raped her during the annual conference of the Cognitive Neuroscience Society in San Francisco ( The New York Times, November 15, 2018, U.S Column, Anemona Hartocollis)

Datum 4.5 is one of the phrases taken from an article entitled "Police arrest of Islamic teacher 
for alleged sexual abuse". It is explained in the article that a teacher of Islamic religion or also known as Ustadz was arrested by the police on charges of sexual abuse. The bold word indicates the author describes a teacher as an actor who actively acts on his target. Datum 4.6 was obtained from an article entitled "Dartmouth Professors Are Accused of Sexual Abuse by 7 Women in Lawsuit", in this news, it was explained that there were seven women who sued three prominent professors from the college. The perpetrator is described as an active party in carrying out the action, as in the sentence, Professor Kelley being the only person who committed an act of "rape".

\section{Passivation}

Passivation is used when the social actors are represented as 'undergoing' the activity, or as being 'at the receiving end of it' (Qanitat, 2015:19). There are two subcategories in it, (1) Subjection and (2) Beneficialization.

\section{Subjection}

Subjection can be realized when a social actor transforms into passive, means is goal in a material process, phenomenon in a mental process, or carrier in an effective attributive process, it can also be realized by circumstantialization through a prepositional phrase with, for instance, against, (Halliday,1985: 43) cited in Van Leeuwen (2008, 32).

4.7 In September, US Catholic bishops said they would set up a hotline for accusations of sexual abuse against bishops and other church leaders, or allegations of cover ups by such people (The Jakarta Post, October 19, 2018, World Column, Bernie Woodal)

4.8 six women accused Mr. Moonves of sexually inappropriate behavior (The New York Times, December 15, 2018, Media Column, John Koblin)

Datum 4.7 obtained from an article entitled "US Justice Department probes Catholic Church sex abuse in Pennsylvania". It explained that sexual abuse cases have been carried out by a priest against a child. The application of subjection is through circumstantialization process, which is done through a prepositional phrase "against". Hence, the position of bishops and church leaders as the actor is treated as an object of discussion. In 4.8, the subjection strategy realized by the material process. It is taken from an article entitled "The Year of Reckoning at CBS: Sexual Harassment Allegations and Attempts to Cover Them Up". The bold word explained clearly that "Mr.Moonves" as an actor or the doer of the action is represented as an object of discussion. Therefore, "Mr.Moonves" is a goal in a material process.

\section{Beneficialisation}

Beneficialization may be realized by participation. The participant that presented is recipient or client to a material process, or receiver in relation to a verbal process (Halliday, 1985) as cited in Van Leeuwen (2008). In this strategy, social actors formed a third party which positively or negatively benefits from the action. Therefore, parties that are directly connected with the main actors can be referred to as social actors.

4.9 ... a student told her mother about the abuse in May. (The Jakarta Post, June 6, 2018, National Column, Fadli)

4.10 The image, which she showed to investigators, did not capture the alleged assault but showed Dr. Krauss' arm over her shoulder with his hand in the air. The New York Times, December 15, 2018, Media Column, John Koblin)

Datum 4.9 which taken from the article entitled "Police arrest Islamic teacher for alleged sexual abuse" confirms that beneficialization is realized by verbal process. 
Table 4.1 verbal process in news

\begin{tabular}{|l|l|l|l|}
\hline A Student & told & Her mother & about the abuse in May. \\
\hline Sayer & Verbal & receiver & vabriage \\
\hline
\end{tabular}

Table 4.1 explain that "Her mother" is a receiver in the verbal process and beneficial in relation to "told". Thus, this indicates that "her mother" is an actor of the clause.

Moreover, datum 4.10 taken from article entitled "The Year of Reckoning at CBS: Sexual Harassment Allegations and Attempts to Cover Them Up". It confirms that beneficialization realized by material processes

Table 4.2 material process in news

\begin{tabular}{|l|l|l|l|l|l|}
\hline The image & which & She & showed & to investigators, & $\begin{array}{l}\text { did not capture the } \\
\text { alleged assault but } \\
\text { showed Dr. Krauss' arm } \\
\text { over her shoulder with } \\
\text { his hand in the air. }\end{array}$ \\
\hline Goal & & Actor & Process & Recipient & \\
\hline
\end{tabular}

Table 4.2 explained that "investigators" who is the third party of the clause, are treated as the actors of the news since they become the Recepient in relation to material process (showed)

\section{Specification}

Specification may be realized by the singular, and can result by several ways, they are, Individualization and Assimilation.

\section{Individualization}

Individualization represents social actors as referred to individually. In this case, the actor is represented in specific characterization. Individualization is found in both newspapers;

4.11 Oscar-winning US actor Kevin Spacey is facing a felony charge for alleged sexual assault of a teenager in a restaurant in 2016, prosecutors said on Monday. ( The Jakarta Post, December 25, 2018, Entertainment Column)

4.12 The orchestra fired the violinist William Preucil, its concertmaster of more than two decades, and Massimo La Rosa, its principal trombonist, after an investigation concluded that they had engaged in sexual misconduct and sexually harassing behavior with multiple women over a period of years ( The New York Times, October 25, 2019, Music Column, Michael Cooper)

Datum 4.11 quoted from the article entitled "Actor Kevin Spacey To Be Charged with Sexual Assault". It confirms that Kevin Spacey as the actor of the news is represented as a specific individual. Besides mentioning the name, the journalist mentions the success or achievement of the actor to give specific reference and explain in more detail the circumstances of the actor. Moreover, datum 4.12 is quoted from an article entitled "Cleveland Orchestra Fires Two Sexual Misconduct". In the same purpose, actor represented by the use of full names along with the work and community, that is "Violinist" and "Trombonist". This helps the reader to have a specific idea about whom the actor is meant to be.

\section{Assimilation}

In the assimilation strategy, the social actor will not be presented as a specific individual. In other words, this strategy is used to generalize social actors, so that readers do not have a clear reference to whom the actors are referred to. In this research, Assimilation only found in The Jakarta Post meanwhile The New York Times mostly presents the actor of the news in their specific attribute. 
4.13 The Church in Chile, Australia and Ireland is also reeling from crises involving sexual abuse of minors with surveys showing the scandal has eroded confidence in the Church and Pope. The Jakarta Post, October 19, 2018, World Column, Bernie Woodal)

Datum 4.13 is taken from an article entitled "US Justice Department probes Catholic Church sex abuse in Pennsylvania". The journalists generalize by not mentioning the social actors or the name of the specific church which were informed within the text. They only mention the name of countries such as "Chile", "Australia" and "The United States". In fact, not all of the church and church leaders in those countries were involved in the sexual abuse case. Also, the author represented the victim on the news by using general terms, which are "minors". Consequently, the reader did not have any specific clue about the victim.

\section{Categorization}

In categorization, social actors can be represented in terms of identities and functions they share with others. In other words, actors are represented based on something inherent in each of them. There are some subdivisions of Categorization, and they are (1) Functionalization, (2) Identification, and (3) Appraisement.

\section{Functionalization}

Functionalization Strategy is used to provide clear information about the function or role of an actor in social life.

4.14 A teacher from Mataram, West Nusa Tenggara, who has been jailed for spreading a recording revealing alleged sexual harassment by her former superior, has pleaded to President Joko “Jokowi”" Widodo to release her. The Jakarta Post, November 14, 2018, National column, Gemma Holliani Cahya)

4.15 One hazing video emerged online. Then another - this one capturing a young student being pinned down by schoolmates in a locker room and sexually assaulted with a broom handle. (The New York Times, November 23, 2018, Canada Column, Catherine Porter)

Datum 4.14 was quoted from an article entitled "Jailed for reporting her sexual offender alleged, Mataram woman cries for help". This confirms that the social actor is represented based on the actor's profession. This realized by using affix -er, while the activity carried out is "teach". In 4.15, the social actor is represented by the role, which is "student". This shows that this strategy is realized by the suffix -ent, while the activity is "study". Besides, the datum is taken from an article entitled "St. Michael's, a Toronto All-Boys School, Is Rocked by Accusations of Sexual Assault".

\section{Identification}

Identification occurs when social actors are defined in terms of what they are. Van Leeuwen (1996) distinguishes three types: classification, relational identification, and physical identification;

Classification refers to conditions when the social actors are represented in terms of the major categories through which different classes of people are differentiated. The categories include age, gender, provenance, class, ethnicity, etc. In this strategy, each newspaper adopted this strategy.

$4.16 \ldots$ the court ruled on Friday that the 37-year-old must serve a six-month sentence and pay a $\mathrm{Rp} 500$ million (US\$33,749) fine after being found guilty of violating Article 27 of the Electronic Information and Transactions (ITE) Law. The Jakarta Post, November 14, 2018, National column, Gemma Holliani Cahya) 
4.17 This week, CBS settled a lawsuit when three women who accused the network - and PBS, which used to broadcast his talk show - of not doing enough to stop Charlie Rose from sexually harassing them. The New York Times, December 15, 2018, Media Column, John Koblin)

Datum 4.16 taken from an article entitled "Jailed for reporting her alleged sexual offender, Mataram woman cries for help". The bold words explained that social actor is represented using age categories. Referring to the contents of the news, the 37-year-old is referring to a victim. This strategy is used to provide information about the attributes of the actor without specifically mention the name of the actor. Besides, Datum 4.17 confirms that actors in sexual crime cases are represented according to gender. Besides, the datum is quoted from an article entitled "The Year of Reckoning at CBS: Sexual Harassment Allegations and Attempts to Cover Them Up".

Besides through classification, social actors are also represented through relational identification strategy. In the strategy, social actors represented in terms of their personal, kinship or work relations to each other.

4.18 "Unruh told reporters the 59-year-old had sexually assaulted her son on the holiday island of Nantucket after plying him with alcohol late at night in a bar in July 2016 (The Jakarta Post, December 25, 2018, Entertainment Column)

4.19 "One hazing video emerged online. Then another — this one capturing a young student being pinned down by schoolmates in a locker room and sexually assaulted with a broom handle. (The New York Times, November 23, 2018, Canada Column, Catherine Porter)

Datum 4.18 taken from the article entitled "Actor Kevin Spacey to be charged with sexual assault" and 4.19 is taken from an article entitled "St. Michael's, a Toronto All-Boys School, Is Rocked by Accusations of Sexual Assaults". Both adopted this strategy to explain the relationship between social actors. In 4.18, this strategy was used to explain the relationship between participants and victims as seen in the bold words. Meanwhile, in 4.19, the strategy is used to explain the relationship between victim and perpetrator.

\section{Appraisement}

Social actors are appraised when they are referred to in terms which evaluate them as good or bad, loved or hated, admired or pitied. This is realized by the set of nouns and idioms that denote such appraisement (and only such appraisement) as, for instance, "the darling," "the bastard," "the wretch," or "thugs" (Van Leeuwen, 2008).

4.20 During the same meeting, Fisipol said it agreed to engage psychologists to provide trauma counseling for "the survivor". (The Jakarta Post, November 7, 2019, National column, Sri Wahyuni and Evi mariani)

4.21 The college encouraged them to continue working with their harassers for four more months. (The New York Times, November 15, 2018, U.S Column, Anemona Hartocollis)

Datum 4.20 was taken from an article entitled "Victim blaming in the latest UGM sex abuse case angers thousands". It revealed that the journalists called social actors as "the survivor". This implies that the journalist evaluates the actor as a good person. This mention leads to the victim's courage to fight for the rights. Meanwhile, datum 4.21 is from an article entitled "Dartmouth Professors Are Accused of Sexual Abuse by 7 Women in Lawsuit". The journalist mentioned social actors as "harasser" which means the actors are identified as someone cruel for doing the action repeatedly.

\section{Nomination}

In this strategy, social actors are presented in terms of their unique identity and are usually 
manifested with proper nouns and divided into formalization (only definite names, with or without honorifics), semi formalization (given a name and a sure name), and informalization (given only names), and also it can be in the form of honorification, the addition of standard titles, ranks,etc., as with "Dr."

4.22 Mr. Bauman was known as a tough-talking, old-school kind of political leader, a style that he took with him from the Bronx when he came west. (The New York Times, November 30, 2018, U.S Column, Adam Nagourney)

4.23 Spacey will be arraigned at Nantucket District Court on January 7 on a charge of indecent assault and battery, according to the district attorney of Cape and Islands, Massachusetts. ( The Jakarta Post, December 25, 2018, Entertainment Column)

Datum in $\mathbf{4 . 2 2}$ is from articles entitled "California Democratic Leader, Facing Sexual Misconduct Allegations, Steps Down". This revealed that social actors are presented by using the last name only. It shows that the journalist uses the formalization strategy. Meanwhile, datum $\mathbf{4 . 2 3}$ is from an article entitled "Actor Kevin Spacey to be charged with sexual assault". This affirms that the social actor in the news also presented by the formalization strategy, this is indicated by the bold word, that is, 'Spacey'.

4.24 Lawrence M. Krauss, a prominent theoretical physicist at Arizona State University, announced on Sunday that he would retire from the university at the end of the academic year after several women accused him of sexual misconduct (The New York Times, October 23, 2018, Science Column, Matthew Haag)

The sentence in $\mathbf{4 . 2 4}$ is quoted from an article entitled "Lawrence Krauss to Retire From Arizona State After Sexual Misconduct Accusations". It presents a social actor with a full name; given name and family name, which means the author uses semiformalization strategy. Moreover, the semiformalization strategy was not found in eight articles collected by researchers from The Jakarta Post.

4.25 Nuril stopped her stammering words to take a breath and wipe her tears (The Jakarta Post, November 14, 2018, National column, Gemma Holliani Cahya)

The sentence in $\mathbf{4 . 2 5}$ taken from the article "Jailed for reporting her alleged sexual offender, Mataram woman cries for help". It presents an actor using the actor's first name. This strategy is called informalization. Meanwhile, from the eight articles that researchers collected from The New York Times, none of the articles used this strategy to refer to a social actor.

4.26 Professor Kelley raped her during the annual conference of the Cognitive Neuroscience Society in San Francisco (The New York Times, November 15, 2018, U.S Column, Anemona Hartocollis)

The sentence in the 4.26 is from an article entitled "Dartmouth Professors Are Accused of Sexual Abuse by 7 Women in Lawsuit". It shows that the social actor is represented with the academic title of the actor, which is "professor". This indicates that the author uses strategy honorification. Besides, honorification is not found in eight sample articles at The Jakarta Post.

\section{Conclusion}

Based on the findings, the researchers formulated some conclusions. First, to detach the actors, both newspapers used suppression and backgrounding strategy. In this strategy, 
similarly, The Jakarta Post and the New York Times mostly represent the victim as a passive agent while the perpetrator portrayed as the active agent who actively takes control over the victim and misused the power to oppress the victim with sexual activity. Moreover, this strategy could direct readers' sympathy into the victim's side then less attention to the perpetrator.

Besides the exclusion strategy, the journalists of The New York Times and The Jakarta Post newspaper also used inclusion strategy which can be observed through the use of activation, passivation, categorization, specification, and nominations using those strategies, the social actors are openly shown and displayed to the readers because the readers are supposed to easily give their thought and response related to the given news. However, in those article provided, the researchers could not find some sub inclusion strategies such as physical identification, generication, and other strategies because there is no indication of the sentence which adopts them. Furthermore, in adopting inclusion, each newspaper had its typical tendency in deciding about which categories the paper wanted to mainly base their references to the main social actors. This suggested that The Jakarta Post tended to invite the reader to be more focus on social actor rather than the case itself. Additionally, The Jakarta Post seemed to expose how participants and the main actor of the news are involved in the sexual case were connected. On the other hand, The New York Time's tendency to represent both perpetrators and victims by using their name as individual indicated that the newspaper attempted to focus the reports more on the crimes themselves rather than the participants involved in the cases.

\section{References}

Amalia, Rosaria Mita. 2019. Textual Analysis of Power of the Government of Indonesia and Aceh in the Helsinki MoU. Teknosastik, 17(1), 1-6.

Ary,Donald, et al. 2002. Introduction to Research in Education. Belmont: Wadsworth.

Creswell, John W. 1998. Qualitative Inquairy and Research Design. California: Sage Publication.

Davari, safoura and Moini M.R. 2016. The Representation of social actors in top notch textbook series: A critical discourse analysis perspective. Journal of Foreign Language Teaching and Research, 4(3), 69-82.

Fairclough, Norman. 1995. Critical Discourse Analysis. London: Longman.

Fairclough, Norman. 2004. Analysing Discourse: Textual Analysis for Social Research. London: Routledge.

Halliday, M.A. K. 1989. Spoken and Written Language. London: Oxford University Press.

Leeuwen, Theo Van.1996. The Representation of social actors. In Caldas and Coulthard (Eds.). Text and Practices: Reading on Critical Discourse Analysis (pp.32-42). London: Routledge.

Leeuwen, Theo Van. 2008. Discourse and Practice: New Tools for Critical Discourse Analysis. New York: Oxford University Press.

Pekkarinen, Anna Greta. 2016. Critical Discourse Analysis of the representation of victims and perpetrators of sexual violence in select US news Articles. Journal of Department of Language Finland, 3(2), 9-11. 
Qanitat, Khat. 2015. Social Actor Representation on Islamic Issues in the New York Times and The Guardian Newspapers (Bachelor Thesis). Retrieved from http://etheses.uinmalang.ac.id/3027/1/113200791.pdf.

Risdaneva. 2018. A critical discourse analysis of women's portrayal in news reporting of sexual violence. Studies in English Language and education, 5(1), 126-136.

World Health Organization. 2012. "Understanding and Addressing Violence Against Women".

https://apps.who.int/iris/bitstream/handle/10665/77434/WHO_RHR_12.37_eng.pdf;j sessionid=5AFB9E129AAF648EB5F49FED985A9E96? sequence=1. (Retrieved on January 9, 2019). 